\title{
Microstructural evolution during hot shear deformation of an extruded fine-grained $\mathrm{Mg}-\mathrm{Gd}-\mathrm{Y}-\mathrm{Zr}$ alloy
}

\author{
R. Alizadeh \\ ${ }^{a}$ School of Metallurgical and Materials Engineering, College of Engineering, \\ University of Tehran, Tehran, Iran (mrbalizadeh@ut.ac.ir)

\begin{abstract}
R. Mahmudi ${ }^{\mathrm{a}^{*}}$
${ }^{a}$ School of Metallurgical and Materials Engineering, College of Engineering, University of Tehran, Tehran,Iran (mahmudi@ut.ac.ir)

*Corresponding author: e-mail: mahmudi@ut.ac.ir;

Phone: +98218208 4137, Fax: +982188006076
\end{abstract}
A.H.W. Ngan ${ }^{\text {b }}$
${ }^{\mathrm{b}}$ Department of Mechanical Engineering, The University of Hong Kong, Pokfulam Road, Hong Kong (hwngan@hku.hk)

T.G. Langdon ${ }^{\mathrm{c}}$

${ }^{\mathrm{c}}$ Materials Research Group, Faculty of Engineering and the Environment, University of Southampton, Southampton SO17 1BJ, U.K. (T.G.Langdon@ soton.ac.uk) 


\title{
Microstructural evolution during hot shear deformation of an extruded fine-grained $\mathrm{Mg}-\mathrm{Gd}-\mathrm{Y}-\mathrm{Zr}$ alloy
}

\author{
R. Alizadeh ${ }^{\mathrm{a}}$, R. Mahmudi ${ }^{\text {a, }}$, A.H.W. Ngan ${ }^{\mathrm{b}}$, T.G. Langdon ${ }^{\mathrm{c}}$ \\ ${ }^{a}$ School of Metallurgical and Materials Engineering, College of Engineering, \\ University of Tehran, Tehran, Iran \\ ${ }^{b}$ Mechanical Engineering Department, The University of Hong Kong, Pokfulam Road, \\ Hong Kong \\ ${ }^{\mathrm{c}}$ Materials Research Group, Faculty of Engineering and the Environment, \\ University of Southampton, Southampton SO17 1BJ, U.K.
}

\begin{abstract}
:
$\mathrm{Mg}-\mathrm{Gd}-\mathrm{Y}-\mathrm{Zr}$ alloys are among recently developed $\mathrm{Mg}$ alloys having superior mechanical properties at elevated temperatures. Dynamic recrystallization (DRX) and rare earth (RE)-rich particles play important roles in enhancing the high temperature strength of these alloys. Accordingly, the microstructural evolution of a fine grained extruded $\mathrm{Mg}-5 \mathrm{Gd}-4 \mathrm{Y}-0.4 \mathrm{Zr}$ alloy was investigated after hot shear deformation in the temperature range of $350-450{ }^{\circ} \mathrm{C}$ using the shear punch testing (SPT) method. The results reveal the occurrence of partial dynamic recrystallization at the grain boundaries at $350{ }^{\circ} \mathrm{C}$ while the fraction of DRX grains increases with increasing deformation temperature. A fully-recrystallized microstructure was achieved after SPT at $450{ }^{\circ} \mathrm{C}$. The Gd-rich and Y-rich cuboid particles, having typical sizes in the range of $\sim 50 \mathrm{~nm}$ to $\sim 3 \mu \mathrm{m}$, show excellent stability and compatibility after hot shear deformation and these particles enhance the high temperature strength during hot deformation at elevated temperatures. The textural evolution, examined using electron backscattered diffraction (EBSD), revealed a non-fibrous basal DRX texture after SPT which is different from the conventional deformation texture.
\end{abstract}

Keywords: Cuboid particles; Hot deformation; $\mathrm{Mg}-\mathrm{Gd}-\mathrm{Y}-\mathrm{Zr}$ alloys; Shear punch testing; Texture

*Corresponding author: e-mail: mahmudi@ut.ac.ir, Phone: +98 218208 4137, Fax: +98 2188006076 


\section{Introduction}

Magnesium alloys based on the $\mathrm{Mg}-\mathrm{Al}-\mathrm{Zn}$ system suffer from poor mechanical properties at elevated temperatures and accordingly attempts have been made to improve these properties through the addition of alloying elements. For example, there are reports that rareearth (RE) elements can greatly improve the microstructural stability of $\mathrm{Mg}$ alloys at high temperatures [1-4]. Among the newly-developed Mg-RE based alloys are $\mathrm{Mg}-\mathrm{Gd}-\mathrm{Y}$ alloys which exhibit superior strength [5-7] and creep resistance [8,9]. In addition, these alloys show the potential for superplasticity in both the fine-grained $[10,11]$ and nano-grained $[12,13]$ states. These exceptional properties originate primarily from the influence of RE elements on the restoration processes and the textural evolution of $\mathrm{Mg}$ alloys at elevated temperatures [14,15] and also from the presence of RE-rich precipitates having superior thermal stability [4]. These results suggest that it would be valuable to investigate the hot deformation of $\mathrm{Mg}-\mathrm{Gd}-\mathrm{Y}$ alloys to obtain a better understanding of the dominant flow mechanisms at these high temperatures.

Some limited research has been conducted recently on the hot deformation of $\mathrm{Mg}-\mathrm{Gd}-\mathrm{Y}$ alloys but these investigations have generally used constitutive analyses and/or processing maps so that only limited information is available on microstructural evolution at elevated temperatures. Generally, discontinuous dynamic recrystallization (DDRX) has been invoked as the most important microstructural restoration process in $\mathrm{Mg}-\mathrm{Gd}-\mathrm{Y}$ alloys at elevated temperatures and a summary of the experimental conditions used in these reports is given in Table1 where all data relate to hot compression [16-20]. The processing condition, the resultant grain size where reported, the testing temperature and the strain rate ranges are all listed in Table 1 and inspection shows that most reports relate to alloys in the cast condition and there is only one investigation of an Mg-Gd-Y alloy in the extruded condition [19]. Furthermore, there 
have been no investigations using other deformation procedures such as shear testing. Thus, despite the important role of RE-rich particles in enhancing the high-temperature strength of $\mathrm{Mg}$ RE alloys, relatively little attention has been devoted to the microstructural evolution and the role of these particles during hot deformation. Furthermore, there are at present no investigations of the textural evolution of $\mathrm{Mg}-\mathrm{Gd}-\mathrm{Y}$ alloys after hot deformation.

While hot compression testing is the most common procedure for hot deformation studies, investigations of hot deformation of metallic alloys by localized testing techniques is of significant interest. Recently, shear punch testing (SPT) needing very small thin samples was successfully used for evaluating the hot deformation characteristics of $\mathrm{Mg}-\mathrm{Li}$ alloys $[21,22]$ and Mg-Gd-Zn alloys [23] through constitutive analysis. Thus, the present investigation was initiated to investigate the microstructural and textural evolution of an $\mathrm{Mg}-5 \mathrm{Gd}-4 \mathrm{Y}-0.4 \mathrm{Zr}$ alloy during hot shear deformation using SPT at different temperatures and strain rates and to determine the underlying restoration processes and also the role of the RE-rich precipitates in enhancing the high-temperature behavior of this alloy.

\section{Experimental material and procedures}

An Mg-5 wt $\%$ Gd-4 wt $\%$ Y-0.4 wt $\%$ Zr alloy was used for this investigation with the alloy prepared from high purity $\mathrm{Mg}$ and $\mathrm{Mg}-30 \mathrm{Gd}, \mathrm{Mg}-30 \mathrm{Yand} \mathrm{Mg}-30 \mathrm{Zr}$ master alloys. Details of the melting and extrusion processes were described earlier [14,24] but, briefly, the required metal was melted in an electric resistance furnace under a protective flux cover, poured into a steel die preheated to $300{ }^{\circ} \mathrm{C}$ using a tilt-casting system to minimize casting defects and melt turbulence and then extruding at $400{ }^{\circ} \mathrm{C}$ with an extrusion ratio of 19:1. The hot shear 
deformation was assessed using SPT and again the details were given earlier [25]. Sample preparation for SPT involved cutting thin disks of $\sim 0.90 \pm 0.05 \mathrm{~mm}$ thickness perpendicular to the extrusion direction (ED) using electro-discharge machining (EDM) and then reducing the thickness by soft grinding to $\sim 0.70 \pm 0.05 \mathrm{~mm}$ to remove any surface roughness. The prepared samples were placed within an SPT fixture having a $2.957 \mathrm{~mm}$ diameter flat cylindrical punch and a $3.044 \mathrm{~mm}$ diameter receiving hole. The load required to deform the sample, $F$, was measured automatically as a function of the punch displacement and the data were recorded using appropriate software to determine the shear stress, $\tau$, on the tested material based on the following relationship [26]

$$
\tau=\frac{F}{\pi D t}
$$

where $t$ is the specimen thickness and $D$ is the average of the punch and die hole diameters. The SPT curves were plotted as shear stress against punch displacement normalized to the initial thickness. The SPT was performed at temperatures of 350,400 and $450{ }^{\circ} \mathrm{C}$ under two shear strain rates, $\dot{\gamma}$, of $3.3 \times 10^{-2}$ and $2.7 \times 10^{-1} \mathrm{~s}^{-1}$ using a screw-driven MTS testing system equipped with a three-zone split furnace.

The microstructures of the samples, both before and after SPT, were characterized using a Hitachi S-3400N variable pressure scanning electron microscope (SEM) and a Hitachi S-4800 field emission gun scanning electron microscope (FEGSEM) after etching the samples in an acetic-picral solution. The crystal structure and chemical composition of the precipitates were examined using an FEI Tecnai G2 20 S-TWIN scanning transmission electron microscope (STEM) with a maximum operating voltage of $200 \mathrm{kV}$. After grinding to $\sim 100 \mu \mathrm{m}$ thickness, the TEM disks were further reduced to $\sim 20 \mu \mathrm{m}$ with a dimpler machine and the TEM samples were 
finally prepared by ion beam milling (IBM). Electron backscattered diffraction (EBSD) was used to study the orientation maps and texture evolution. The specimen preparation for EBSD involved grinding with $\mathrm{SiC}$ paper and diamond paste polishing followed by vibratory polishing with an alcohol-based alumina solution.

\section{Experimental results}

\section{Microstructure before SPT}

Representative SEM micrographs at two different magnifications are shown in Fig. 1 corresponding to the plane perpendicular to ED. It is apparent that the microstructure after hot extrusion at $400{ }^{\circ} \mathrm{C}$ consists of fine equiaxed grains with an average size of $\sim 4.6 \pm 0.2 \mu \mathrm{m}$ indicating the occurrence of dynamic recrystallization (DRX) and with small cuboid particles which appear to be rich in RE located both at the grain boundaries and within the grains. The microstructure in the transverse direction (TD) on the plane parallel to ED is shown in Fig. 2 at two different magnifications. These micrographs show there are no elongated grains in either the ED or TD and it is reasonable to conclude that the DRX is complete. Regarding the DRX mechanism of the alloy during the extrusion process, it was shown earlier [14] that new DRX grains form at the original grain boundaries during hot deformation and therefore it was concluded that the DRX can be considered as the main mechanism of recrystallization. The microstructure of the $\mathrm{Mg}-5 \mathrm{Gd}-4 \mathrm{Y}-0.4 \mathrm{Zr}$ alloy, extruded with lower extrusion ration of $8: 1$, is shown in Fig. 3 to explore better the formation of DRX grains during deformation. As can be observed in this figure, a necklace structure was developed after the extrusion process, which can 
be considered as an indication of the occurrence of the DRX mechanism. The formation of newly-developed DRX grains at the original grain boundaries is shown in Fig. $3 \mathrm{~b}$.

High magnification FEGSEM micrographs of the particles are shown in Fig. 4 which confirms that the RE-rich particles are present in the form of small cuboidal shapes. In Fig. 4a there are two cuboidal particles, one formed at the grain boundary and the other within a grain. A cuboid particle embedded at a grain boundary is shown in Fig. $4 \mathrm{~b}$ at a higher magnification. In addition to these isolated particles, some agglomerated particles were also present as in Figs. 4c and d. Comprehensive microstructural characterization showed that the sizes of these cuboid particles varied within the range of $\sim 50 \mathrm{~nm}$ up to $\sim 3 \mu \mathrm{m}$.

The chemical compositions of the cuboidal particles were checked qualitatively by SEM using an energy-dispersive X-ray spectroscopy (EDS) line scan and the results are shown in Fig. 5. These results provide a clear demonstration that the particles are rich in Gd and Y. Elemental maps for $\mathrm{Mg}, \mathrm{Gd}$ and $\mathrm{Y}$ are also shown in Fig. 6 for the agglomerated particles from Fig. 4d. In accordance with the results of Fig. 5, the agglomerated cuboidal particles are rich in Gd and $\mathrm{Y}$ while also containing small amounts of $\mathrm{Mg}$. In order to study the chemical composition of these particles quantitatively, a TEM-EDS analysis was performed on some selected particles and a typical result is summarized in Fig. 7. The results indicate that the cuboidal particle in Fig.7a is rich in $\mathrm{Gd}$ and $\mathrm{Y}$ and, according to the atomic concentration values, the chemical composition is close to $\mathrm{Mg}_{2}(\mathrm{Gd}, \mathrm{Y})$. The crystal structure of the precipitate was also studied through selected area electron diffraction (SAED) and the results are shown in Fig. $7 \mathrm{~b}$ where the pattern was indexed as face-centered cubic (fcc) with a lattice parameter of $\sim 0.54 \pm 0.02 \mathrm{~nm}$. Similar fcc crystal structures with lattice parameters in the range $\sim 0.54$ to $0.56 \mathrm{~nm}$ were reported earlier for cuboid MgRE precipitates [14,27-31]. 


\section{SPT results}

Shear punch test curves are shown in Fig. 8 for temperatures of 350,400 and $450{ }^{\circ} \mathrm{C}$ under shear strain rates of (a) $3.3 \times 10^{-2}$ and (b) $2.7 \times 10^{-1} \mathrm{~s}^{-1}$. It is evident that the flow behavior depends strongly on both temperature and strain rate, thereby suggesting that different deformation mechanisms may operate at different temperatures and strain rates. Thus, the microstructures of the samples will be affected by these different mechanisms after deformation under different conditions and accordingly it is necessary to examine the microstructural evolution in more detail.

\section{Microstructural and textural evolution after SPT}

The microstructural evolution after hot shear deformation was examined by inspecting the cross-sections of the hot deformed samples using SEM and FEGSEM. A schematic illustration of the SPT sample showing different areas of the sample both before and after deformation, together with a low magnification SEM micrograph of a sample after SPT is given in Fig. 9. Three important areas may be identified on each sample; deformation (1), the die (2) and under the punch (3). Since almost all of the shear deformation occurs within the deformation area, most of the microstructural characterizations were focused on this area. However, for a direct comparison with the microstructure of the material experiencing a high temperature but no shear deformation, the microstructure was also examined in the die area. The microstructural evolution was also examined under the punch but these results were essentially identical to those obtained in the die area. 
The microstructures of the material after SPT at $350{ }^{\circ} \mathrm{C}$ under a shear strain rate of $2.7 \times$ $10^{-1} \mathrm{~s}^{-1}$ are shown in Fig. 10 where (a-d) are within the deformation area and (e,f) are in the die area. It is clear that the grains are deformed and elongated in the shear direction and the grain boundaries are thickened in the deformation area whereas by moving from the deformation area towards the die area the grains reasonably retain their original un-deformed shapes and the grain boundaries are thinner. These features indicate that partial DRX occurs at the original grain boundaries at $350{ }^{\circ} \mathrm{C}$ but the deformed grains retain their elongated shapes. By increasing the deformation temperature to $400{ }^{\circ} \mathrm{C}$, the microstructure becomes more uniform in the deformation area in Fig. 11a-c and there are almost no elongated grains except in some small areas as within the area delineated by the broken line in Fig. 11c. This indicates that increasing the temperature form 350 to $400{ }^{\circ} \mathrm{C}$ leads to a replacement of the deformed grains by newly-formed DRX grains which are nucleated at the grain boundaries of the original grains.

The microstructures of the material after SPT deformation at $450{ }^{\circ} \mathrm{C}$ under two shear strain rates of $3.3 \times 10^{-2} \mathrm{~s}^{-1}$ and $2.7 \times 10^{-1} \mathrm{~s}^{-1}$ are shown in Figs. 12 and 13, respectively, where (ac) relate to the deformation area and (d) is for the die area. It is apparent that fine equiaxed grains are formed in the deformation area and these grains are finer than in the die area. Also, in contrast to the lower deformation temperature, no elongated grains are found in the deformation area which indicates the occurrence of complete DRX at $450{ }^{\circ} \mathrm{C}$. However, the grain sizes are relatively larger than those obtained at 400 and $350{ }^{\circ} \mathrm{C}$. Concerning the effect of strain rate, according to the microstructures of the alloy shown in Figs. 12 and 13 for respective shear strain rates of $3.3 \times 10^{-2}$ and $2.7 \times 10^{-1} \mathrm{~s}^{-1}$, it is observed that fine equiaxed grains are formed at $450{ }^{\circ} \mathrm{C}$ irrespective of the applied strain rates. Additionally, no distinct differences were detected 
between the grain sizes of the material in the deformation areas of the samples deformed under different strain rates.

Since RE-rich particles play an important role in enhancing superior strength of $\mathrm{Mg}-\mathrm{Gd}-$ $\mathrm{Y}$ alloys at elevated temperatures, it is of interest to examine the morphologies of these particles after hot shear deformation. Accordingly, the morphology of the cuboid particles after hot shear deformation at $400{ }^{\circ} \mathrm{C}$ under shear strain rates of $3.3 \times 10^{-2}$ and $2.7 \times 10^{-1} \mathrm{~s}^{-1}$ were examined at high magnifications through FEGSEM and the results are presented in Fig. 14 showing the shape, size and distribution of these particles. All micrographs were taken in the deformation area. Inspection shows that the Gd- and Y-rich cuboid particles do not undergo any significant change in shape, fragmentation or deformation while the magnesium matrix is severely deformed within the deformation area. Thus, these particles retain their original shapes. Furthermore, no cracks or voids were detected around these particles even at high magnifications. All of these features demonstrate the excellent thermal stability of these particles and also their compatibility with the Mg matrix during deformation, where both of these factors will enhance the high temperature strength properties of $\mathrm{Mg}-\mathrm{Gd}-\mathrm{Y}$ alloys. An additional important point is that no newly-formed fine grains were observed around any of the cuboid particles.

In addition to the shape and size of the newly-formed grains due to the DRX during hot shear deformation, the crystallographic orientations of these grains is important because it may affect the high-temperature mechanical properties of the material. Accordingly, the orientation maps of the grains after SPT at $450{ }^{\circ} \mathrm{C}$ were obtained by EBSD and the results are shown in Fig.15. It is readily apparent from Figs. 15a and $\mathrm{b}$ that the grains are equiaxed in the shear deformation area and there are no elongated grains. Therefore, it is concluded that complete DRX occurs during hot shear deformation of the alloy at $450{ }^{\circ} \mathrm{C}$. The corresponding pole figures 
are shown in Fig.15c for the (0001) and (1010) planes and it is apparent that there is a relatively strong basal texture with a maximum intensity of 7.8 MRD (multiplies of random distribution). A comparison of this texture with the initial texture before SPT is presented in the next section.

\section{Discussion}

\section{Microstructural evolution after hot shear deformation}

A comparison of Figs. 10-13 demonstrates that, although there is some DRX in the $\mathrm{Mg}-5 \mathrm{Gd}-4 \mathrm{Y}-0.4 \mathrm{Zr}$ alloy even at a temperature of $350{ }^{\circ} \mathrm{C}$, complete DRX occurs only at $450{ }^{\circ} \mathrm{C}$. The microstructure of the material after hot shear deformation at $350{ }^{\circ} \mathrm{C}$ consisted of deformed grains which are surrounded by a typical necklace-like structure which is produced by the DRX. Thus, the DRX occurs only locally at the grain boundaries of the original grains at $350{ }^{\circ} \mathrm{C}$ and therefore very fine grains are formed at the grain boundaries while the original grains remain deformed and elongated in the direction of shear deformation. These features are consistent with the discontinuous dynamic recrystallization (DDRX) mechanism which is generally considered the dominant recrystallization mechanism in $\mathrm{Mg}$ alloys. By increasing the temperature to $400{ }^{\circ} \mathrm{C}$, DRX occurs more readily and leads to a thickening of the bands of newly-formed DRX grains towards the centers of the original grains. Except in some small areas, almost all of the microstructure is recrystallized at $400{ }^{\circ} \mathrm{C}$. Complete recrystallization occurs by increasing the deformation temperature to $450{ }^{\circ} \mathrm{C}$ where fully recrystallized equiaxed grains are formed within the deformation area.

In comparing with earlier studies of $\mathrm{Mg}-\mathrm{Gd}-\mathrm{Y}$ alloys, it is noted that the present results are consistent with those reported for other similar alloys [16-20]. For example, it was reported 
that grain growth occurs at $500{ }^{\circ} \mathrm{C}$ in an extruded $\mathrm{Mg}-8.90 \mathrm{Gd}-5.11 \mathrm{Y}-3.10 \mathrm{Zn}-0.47 \mathrm{Zr}$ alloy but fine DRX grains form at $400{ }^{\circ} \mathrm{C}$ [19]. Also, the temperature range of $375-450{ }^{\circ} \mathrm{C}$ was suggested earlier as the appropriate temperature range for DRX of an as-cast and homogenized $\mathrm{Mg}-9.3 \mathrm{Gd}-$ 2.9Y $-0.3 \mathrm{Zr}$ alloy [17]. A microstructural characterization of a hot compressed as-cast binary $\mathrm{Mg}-1.5 \mathrm{Gd}$ alloy at $400{ }^{\circ} \mathrm{C}$ also revealed the local occurrence of DRX at the original grain boundaries and the development of necklace-like structures [32]. However, static annealing of these samples at $450{ }^{\circ} \mathrm{C}$ for $1 \mathrm{~h}$ resulted in fully recrystallized microstructures [33].

It should be noted that the hot deformation behavior of the $\mathrm{Mg}-\mathrm{Gd}-\mathrm{Y}-\mathrm{Zr}$ alloy in this investigation is different from conventional $\mathrm{Mg}$ alloys without the presence of $\mathrm{RE}$ elements. Although the DRX is the dominant recrystallization mechanism in both RE-containing and REfree magnesium alloys, there are some fundamental differences between their recrystallization behaviors. These differences are attributed to the role of the RE elements in delineating the onset temperature of recrystallization, the amount of stored energy [32], and the crystallographic texture of the newly-formed DRX grains [14,33].As an example, while DRX occurs at grain boundaries of an AZ31 alloy at $300{ }^{\circ} \mathrm{C}$, there was no evidence for the presence of recrystallized grains in the microstructure of an $\mathrm{Mg}-\mathrm{Gd}$ alloy at this temperature [32]. Accordingly, it is concluded that $350{ }^{\circ} \mathrm{C}$ is the temperature for the onset of recrystallization in the present $\mathrm{Mg}-\mathrm{Gd}-$ Y-Zr alloy as observed in Fig. 10.

The higher onset temperature for the RE-containing alloys is due to the relative activity of different deformation systems in RE-containing alloys which is different from magnesium alloys without RE elements. Thus, the RE elements usually segregate at grain boundaries [14,34,35] and dislocations [36], dissolve in the Mg-matrix and/or form clusters in the interiors of the grains [37] in addition to forming RE-rich particles. Accordingly, due to the low diffusion 
rates of these elements in magnesium, the RE elements may retard recrystallization so that higher temperatures are required for the onset of recrystallization in RE-containing $\mathrm{Mg}$ alloys. In this respect, the diffusion coefficients of $\mathrm{Y}$ and $\mathrm{Gd}$ in $\mathrm{Mg}$ are similar but they are almost one order of magnitude lower than for $\mathrm{Al}$ and $\mathrm{Zn}$ which are the conventional alloying elements in magnesium [38,39].

In addition to DRX, another important feature of the microstructure of the $\mathrm{Mg}-5 \mathrm{Gd}-4 \mathrm{Y}-$ $0.4 \mathrm{Zr}$ alloy after hot shear deformation is the stability of the Gd-rich and Y-rich cuboid particles at high deformation temperatures which serves to enhance the high temperature strength of these alloys. The results in this investigation show there is no deformation, coarsening or fragmentation of these particles during hot shear deformation and additionally it seems that the dominant recrystallization mechanism of the material in the experimental temperature range is DDRX. Thus, there is no evidence for particle-stimulated nucleation (PSN) since no newlyformed grains were formed around the cuboid particles.

\section{Textural evolution after hot shear deformation}

In addition to the shape and size of the grains, the occurrence of DRX may also alter the crystallographic orientation of the grains and this determines the dominant texture of the material. Accordingly, the texture of the alloy was studied after hot shear deformation at $450{ }^{\circ} \mathrm{C}$ (Fig. 15) and it is now valuable to compare this result with the initial texture before SPT. The texture of the extruded $\mathrm{Mg}-5 \mathrm{Gd}-4 \mathrm{Y}-0.4 \mathrm{Zr}$ alloy before SPT was discussed in detail in an earlier report [14] and thus it is described only briefly for comparison purposes. 
It was shown earlier that the texture of the extruded $\mathrm{Mg}-5 \mathrm{Gd}-4 \mathrm{Y}-0.4 \mathrm{Zr}$ alloy is different from RE-free Mg alloys wherein the basal planes are aligned parallel to the extrusion direction. In practice, the basal planes of the $\mathrm{Mg}-5 \mathrm{Gd}-4 \mathrm{Y}-0.4 \mathrm{Zr}$ alloy show an almost fibrous texture with an angle of about $60^{\circ}$ between the ED and the normal vector of the basal planes. Therefore, this state can be considered as the initial texture of the material before SPT. After SPT at high temperatures, it is expected that the dominant texture is again a basal texture where basal planes are aligned in the direction of material flow in the sheared area due to the applied mechanical strain within the deformation area. However, the texture of the material in Fig. 15 is different and shows similarities to the trends reported earlier for the extruded alloy [14]. Thus, the dynamically recrystallized grains show a strong non-fibrous basal texture with a maximum intensity of 7.8 MRD. The preferred orientation of the basal planes is such that the angle between the normal direction and the transverse direction is about $-75^{\circ}$ on the $X$ axis and about $10^{\circ}$ on the $Y$ axis. This contrasts with the general behavior of RE-free $\mathrm{Mg}$ alloys where the deformation and recrystallization textures are similar [40]. It is concluded, therefore, that the RE elements alter the DRX texture after hot shear deformation where this is similar to results reported earlier for other modes of deformation such as hot extrusion [14] and hot compression [32,33]. This difference is attributed to the segregation of RE elements at the grain boundaries and dislocation cores and also to the slow diffusivity of $\mathrm{Gd}$ and $\mathrm{Y}$ in $\mathrm{Mg}$ where these elements impede the movement of dislocations and grain boundaries through a solute drag effect [14]. 


\section{Conclusions}

The microstructural and textural evolutions of an extruded $\mathrm{Mg}-5 \mathrm{Gd}-4 \mathrm{Y}-0.4 \mathrm{Zr}$ alloy were evaluated after hot shear deformation by shear punch testing in the temperature range of $350-450{ }^{\circ} \mathrm{C}$ and the following results were achieved:

1. The DRX starts at the grain boundaries of the deformed original grains and produces necklace-like structures at low deformation temperatures thereby demonstrating discontinuous dynamic recrystallization as the dominant restoration process during hot shear deformation.

2. While the original grains were not recrystallized after deformation at $350{ }^{\circ} \mathrm{C}$, some nonrecrystallized deformed grains were detected in the microstructure of the material after SPT at $400{ }^{\circ} \mathrm{C}$. By further increasing the SPT temperature to $450{ }^{\circ} \mathrm{C}$, a fully recrystallized microstructure was obtained with well-defined equiaxed grains.

3. The Gd-rich and Y-rich cuboid particles retained their original shapes and sizes after hot shear deformation. No cracks, voids or fragmentation were observed around these particles. The stability of these particles,and their compatibility with the Mg matrix, are important parameters in enhancing the high temperature strength of $\mathrm{Mg}-\mathrm{Gd}-\mathrm{Y}$ alloys.

4. EBSD orientation maps demonstrate a fully-recrystallized microstructure after SPT at $450{ }^{\circ} \mathrm{C}$ with a non-fibrous basal DRX texture which is different from the conventional deformation texture.

\section{Acknowledgments}

The authors thank the Iran National Science Foundation (INSF) for support of this work under Grant No. 94028861. 


\section{References}

[1] Boehlert CJ (2007) The tensile and creep behavior of Mg-Zn alloys with and without $\mathrm{Y}$ and $\mathrm{Zr}$ as ternary elements. J Mater Sci 42:3675-3684.

[2] Ning ZL, Wang GJ, Cao FY, Sun JF, Du JF (2009) Tensile deformation of a Mg$2.54 \mathrm{Nd}-0.26 \mathrm{Zn}-0.32 \mathrm{Zr}$ alloy at elevated temperature. J Mater Sci 44:4264-4269.

[3] Mahmudi R, Kabirian F, Nematollahi Z (2011) Microstructural stability and hightemperature mechanical properties of AZ91 and AZ91+2RE magnesium alloys. Mater Des32:2583-2589.

[4] Alizadeh R, Mahmudi R, Ngan AHW, Langdon TG (2015) Microstructural stability and grain growth kinetics in an extruded fine-grained $\mathrm{Mg}-\mathrm{Gd}-\mathrm{Y}-\mathrm{Zr}$ alloy. J Mater Sci 50: 4940-4951.

[5] Yao-Bo Hu, Juan Deng, Chong Zhao, Fu-Sheng Pan, Jian Peng (2011) Microstructure and mechanical properties of $\mathrm{Mg}-\mathrm{Gd}-\mathrm{Zr}$ alloys with low gadolinium contents. J Mater Sci 46:5838-5846.

[6] Movahedi-Rad A, Mahmudi R (2014) Effect of Ag addition on the elevated-temperature mechanical properties of an extruded high strength $\mathrm{Mg}-\mathrm{Gd}-\mathrm{Y}-\mathrm{Zr}$ alloy. Mater Sci Eng A 614:62-66.

[7] Cunlong Wang, Guohua Wu, Enrique J. Lavernia, Wenjiang Ding (2017) Influences of heat treatment on microstructural evolution and tensile behavior of squeeze-cast $\mathrm{Mg}-\mathrm{Gd}-$ Y-Zr alloy. J Mater Sci 52:1831-1846.

[8] Mordike BL (2002) Creep resistant magnesium alloys. Mater Sci Eng A 324:103-112.

[9] Yin DD, Wang QD, Boehlert CJ, Ding WJ (2012) Creep and fracture behavior of as-cast Mg-11Y-5Gd-2Zn-0.5Zr (wt\%). J Mater Sci 47:6263-6275.

[10] Alizadeh R, Mahmudi R, Langdon TG (2014) Superplasticity of a fine-grained Mg9Gd-4Y-0.4Zr alloy evaluated using shear punch testing. J Mater Res Technol3:228232.

[11] Alizadeh R, Mahmudi R, Ngan AHW, Huang Y, Langdon TG (2016) Microstructure, texture and superplasticity of a fine-grained $\mathrm{Mg}-\mathrm{Gd}-\mathrm{Zr}$ alloy processed by equal-channel angular pressing. MetallMater Trans47A:6056-6069.

[12] Alizadeh R, Mahmudi R, Ngan AHW, Huang Y, Langdon TGL (2016) Superplasticity of a nano-grained $\mathrm{Mg}-\mathrm{Gd}-\mathrm{Y}-\mathrm{Zr}$ alloy processed by high-pressure torsion. Mater Sci Eng A 561:786-794. 
[13] Alizadeh R, Mahmudi R, Pereira PHR, Huang Y, Langdon TG (2017) Microstructural evolution and superplasticity in an $\mathrm{Mg}-\mathrm{Gd}-\mathrm{Y}-\mathrm{Zr}$ alloy after processing by different $\mathrm{SPD}$ techniques. Mater Sci Eng A 682:577-585.

[14] Alizadeh R, Mahmudi R, Ngan AHW, Langdon TG (2016) An unusual extrusion texture in $\mathrm{Mg}-\mathrm{Gd}-\mathrm{Y}-\mathrm{Zr}$ alloys. Adv Eng Mater18:1044-1049.

[15] Imandoust A, Barrett CD, Al-Samman T, Inal KA, El Kadiri H (2017) A review on the effect of rare-earth elements on texture evolution during processing of magnesium alloys. J Mater Sci 52:1-29.

[16] Ma ML, Zhang K, Li XG (2008) Hot deformation behavior of rare earth magnesium alloy without pre-homogenization treatment. Tran. Nonferrous Met China 18:132-139.

[17] Chen B, Zhou WM, Li S, Li XL, Lu C (2013) Hot Compression Deformation Behavior and Processing Maps of Mg-Gd-Y-Zr Alloy. J Mater Eng Perform 22:2458-2466.

[18] Xia X, Chen Q, Zhang K, Zhao Z, Ma M, Li X, Li Y (2013) Hot deformation behavior and processing map of coarse-grained $\mathrm{Mg}-\mathrm{Gd}-\mathrm{Y}-\mathrm{Nd}-\mathrm{Zr}$ alloy. Mater Sci Eng A 587: 283-290.

[19] Xia X, Chen Q, Li J, Shu D, Hu C, Huang S, Zhao Z (2014) Characterization of hot deformation behavior of as-extruded $\mathrm{Mg}-\mathrm{Gd}-\mathrm{Y}-\mathrm{Zn}-\mathrm{Zr}$ alloy. J Alloys Compd 610:203211.

[20] Lu G, Xie Z, Zhang Z, Yang Y, Li B (2014) Hot compression deformation behavior of Mg-Gd-Y-Zn-Zr alloy. Appl Mech Mater 680:15-22.

[21] Karami M, Mahmudi R (2012) Hot shear deformation constitutive analysis of an extruded $\mathrm{Mg}-6 \mathrm{Li}-1 \mathrm{Zn}$ alloy. Mater Lett81:235-238.

[22] Karami M, Mahmudi R (2014) Hot shear deformation constitutive analysis and processing map of extruded $\mathrm{Mg}-12 \mathrm{Li}-1 \mathrm{Zn}$ bcc alloy. Mater Des 53:534-539.

[23] Sarebanzadeh M, Mahmudi R, Roumina R (2015) Constitutive analysis and processing map of an extruded $\mathrm{Mg}-3 \mathrm{Gd}-1 \mathrm{Zn}$ alloy under hot shear deformation. Mater Sci Eng A637:155-161.

[24] Alizadeh R, Mahmudi R (2011) Effects of Sb addition on the modification of $\mathrm{Mg}_{2} \mathrm{Si}$ particles and high-temperature mechanical properties of cast $\mathrm{Mg}-4 \mathrm{Zn}-2 \mathrm{Si}$ alloy. J Alloys Compd 509:9195-9199.

[25] Mahmudi R, Alizadeh R, Azhari Sh (2013) Strain rate sensitivity of equal-channel angularly pressed $\mathrm{Sn}-5 \mathrm{Sb}$ alloy determined by shear punch test. Mater Lett 97:44-46. 
[26] Hankin GL, Toloczko MB, Johnson KI, Khaleel MA, Hamilton ML, Garner FA, Davies RW, Faulkner RG (2000) ASTM STP 1366:1018-1028.

[27] Park WJ, Park H, Kim DH, Kim NJ (1994) Structure and decomposition behavior of rapidly solidified Mg-Nd-X (X=Al,Si) Alloys. Mater Sci Eng A179-180:637-640.

[28] Vostry P, Smola B, Stulikova I, Von Buch F, Mordike BL (1999) Microstructure evolution in isochronally heat treated Mg-Gd alloys. Phys Stat Solidi175A:491-500.

[29] Li D, Wang Q, Ding W (2006) Characterization of phases in Mg-4Y-4Sm-0.5Zr alloy processed by heat treatment. Mater Sci Eng A 428:295-300.

[30] He SM, Zeng XQ, Peng LM, Gao X, Nie JF, Ding WJ (2007) Microstructure and strengthening mechanism of high strength $\mathrm{Mg}-10 \mathrm{Gd}-2 \mathrm{Y}-0.5 \mathrm{Zr}$ alloy. $\mathrm{J}$ Alloy Compd427:316-323.

[31] Yang Z, Wang ZH, Duan HB, Guo YC, Gao PH, Li LP (2015) Microstructure evolution of Mg-6Gd-2Y alloy during solid solution and aging process. Mater Sci Eng A 631: $160-165$.

[32] Stanford N, Callaghan MD, de Jong B (2013) The effect of rare earth elements on the behaviour of magnesium-based alloys: Part 1-Hot deformation behavior. Mater Sci Eng A 565:459-468.

[33] Stanford N (2013) The effect of rare earth elements on the behaviour of magnesiumbased alloys: Part 2- recrystallisation and texture development. Mater Sci Eng A 565:469-475.

[34] Stanford N, Atwell D, Barnett MR (2010) The effect of Gd on the recrystallisation, texture and deformation behaviour of magnesium-based alloys. Acta Mater 58:67736783.

[35] Stanford N, Sha G, Xia JH, Ringer SP, Barnett MR (2011) Solute segregation and texture modification in an extruded magnesium alloy containing gadolinium. Scr Mater 65: 919-921.

[36] Stanford N, Sabirov I, Sha G, LaFontaine A, Ringer SP, Barnett MR (2010) Effect of Al and $\mathrm{Gd}$ solutes on the strain rate sensitivity of magnesium alloys. Metall Mater Trans 41A:734-743.

[37] Stanford N, Sha G, La Fontaine A, Barnett MR, Ringer SP (2009) Atom probe tomography of solute distributions in Mg-based alloys. Metall Mater Trans 40A:24802487. 
[38] Das SK, Kim YM, Ha TK, Gauvin R, Jung IH (2013) Anisotropic diffusion behavior of $\mathrm{Al}$ in Mg: Diffusion couple study using Mg single crystal. Metall Mater Trans 44A:25392547.

[39] Das SK, Kang YB, Ha T (2014) Thermodynamic modeling and diffusion kinetic experiments of binary $\mathrm{Mg}-\mathrm{Gd}$ and $\mathrm{Mg}-\mathrm{Y}$ systems. Acta Mater 71:164-175.

[40] Al-Samman T, Gottstein G (2008) Dynamic recrystallization during high temperature deformation of magnesium. Mater Sci Eng A 490:411-420. 


\section{Legends}

Table 1 Summary of literature data on the hot deformation of $\mathrm{Mg}-\mathrm{Gd}-\mathrm{Y}$ alloys.

Fig. 1. SEM micrographs of the alloy in the ED showing (a) the grain structure, and (b) the distribution of the second phase particles.

Fig. 2. SEM micrographs of the alloy in the TD showing (a) the grain structure, and (b) the distribution of particles.

Fig. 3. SEM micrographs of the alloy, extruded with low ratio of $8: 1$, showing (a) the necklace structure, and (b) formation of new DRX grains at the original grain boundaries.

Fig. 4 FEGSEM micrographs of the alloy showing the positions, shapes and sizes of some representative cuboid particles.

Fig. 5 SEM-EDS line scan along A-B showing the results for Mg, Gd and Y.

Fig. 6 (a) SEM micrograph of agglomerated cuboid particles and the corresponding elemental maps for (b) Mg, (c) Gd and (d) Y.

Fig. 7 (a) TEM micrograph and (b) corresponding SAED pattern of one of the cuboid particles with zone axis parallel to [001].

Fig. 8 SPT curves at different temperatures for shear strain rates of (a) $3.3 \times 10^{-2} \mathrm{~s}^{-1}$ and (b) $2.7 \times$ $10^{-1} \mathrm{~s}^{-1}$.

Fig. 9 (a) Schematic illustration of a sample before and after SPT and (b) a low magnification SEM micrograph of a sample after SPT showing areas corresponding to deformation (1), the die (2) and under the punch (3).

Fig. 10 SEM micrographs of the material after SPT at $350{ }^{\circ} \mathrm{C}$ under a strain rate of $2.7 \times 10^{-1} \mathrm{~s}^{-1}$ : (a,b) deformation area and adjacent regions, $(\mathrm{c}, \mathrm{d})$ deformation area and $(\mathrm{e}, \mathrm{f})$ die area.

Fig. 11 SEM micrographs of the material after SPT at $400{ }^{\circ} \mathrm{C}$ under a strain rate of $2.7 \times 10^{-1} \mathrm{~s}^{-}$ ${ }^{1}$ :(a) deformation area and adjacent region, $(b, c)$ deformation area and (d) die area.

Fig. 12 SEM micrographs of the material after SPT at $450{ }^{\circ} \mathrm{C}$ undera strain rate of $3.3 \times 10^{-2} \mathrm{~s}^{-1}$ : (a) deformation area and adjacent regions, (b,c) deformation area and (d) die area.

Fig. 13 SEM micrographs of the material after SPT at $450{ }^{\circ} \mathrm{C}$ under a strain rate of $2.7 \times 10^{-1} \mathrm{~s}^{-}$ ${ }^{1}$ :(a,b) deformation area and adjacent regions, (c) deformation area and (d) die area.

Fig. 14 Representative high magnification FEGSEM micrographs of the material in the deformation area showing the morphologies of cuboid particles after hot shear deformation at $400{ }^{\circ} \mathrm{C}$. 
Fig. 15 (a,b) EBSD orientation maps and (c) pole figures after SPT at $450{ }^{\circ} \mathrm{C}$ under a strain rate of $3.3 \times 10^{-2} \mathrm{~s}^{-1}$. 

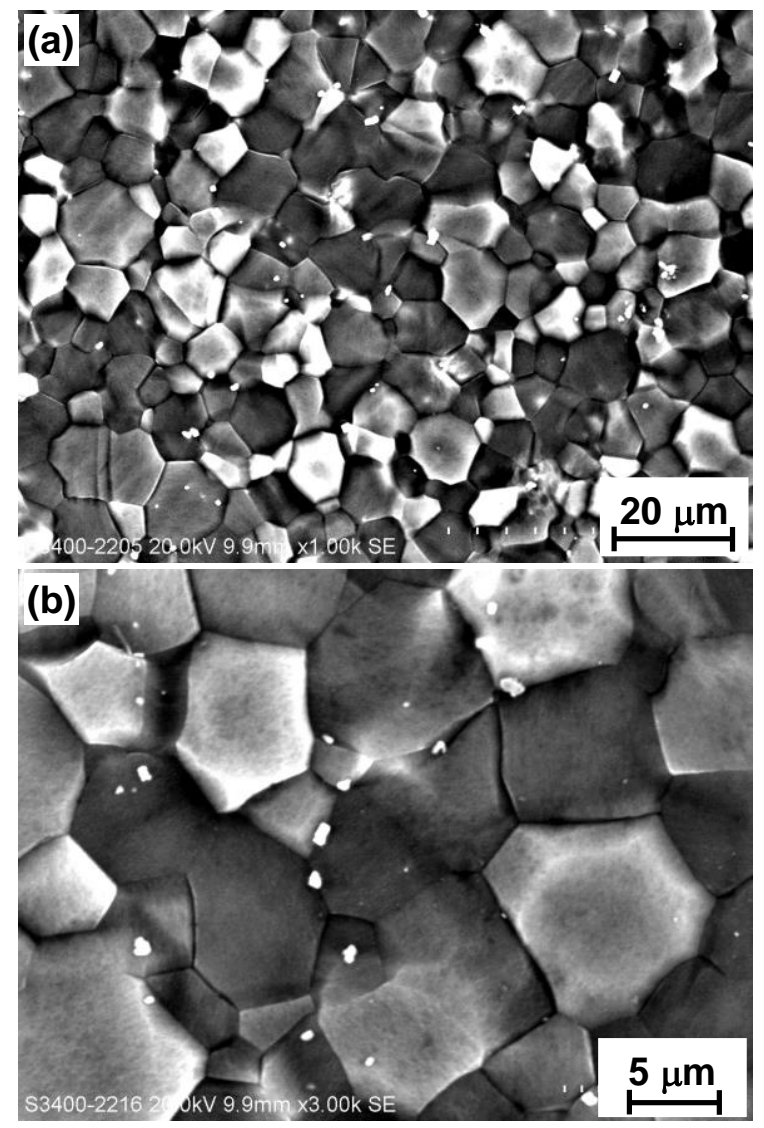

Fig. 1. SEM micrographs of the alloy in the ED direction showing (a) the grain structure and (b) the distribution of the second phase particles. 


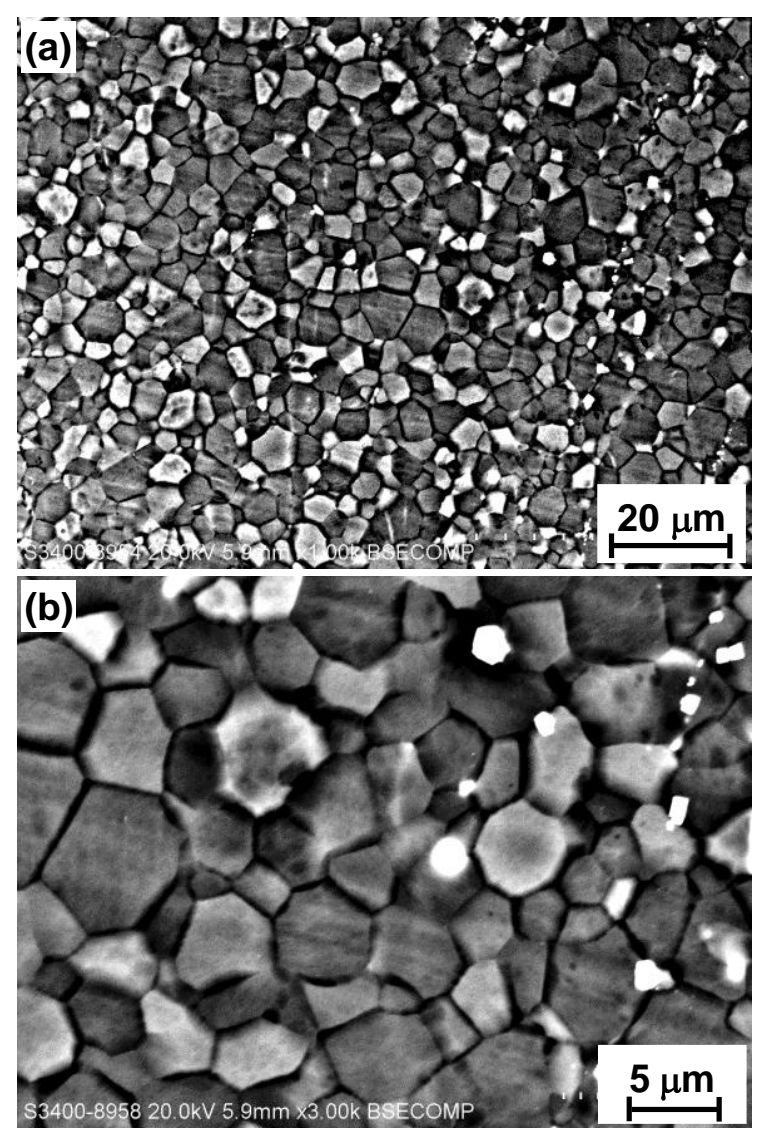

Fig. 2. SEM micrographs of the alloy in the TD direction showing (a) the grain structure and (b) the distribution of particles. 


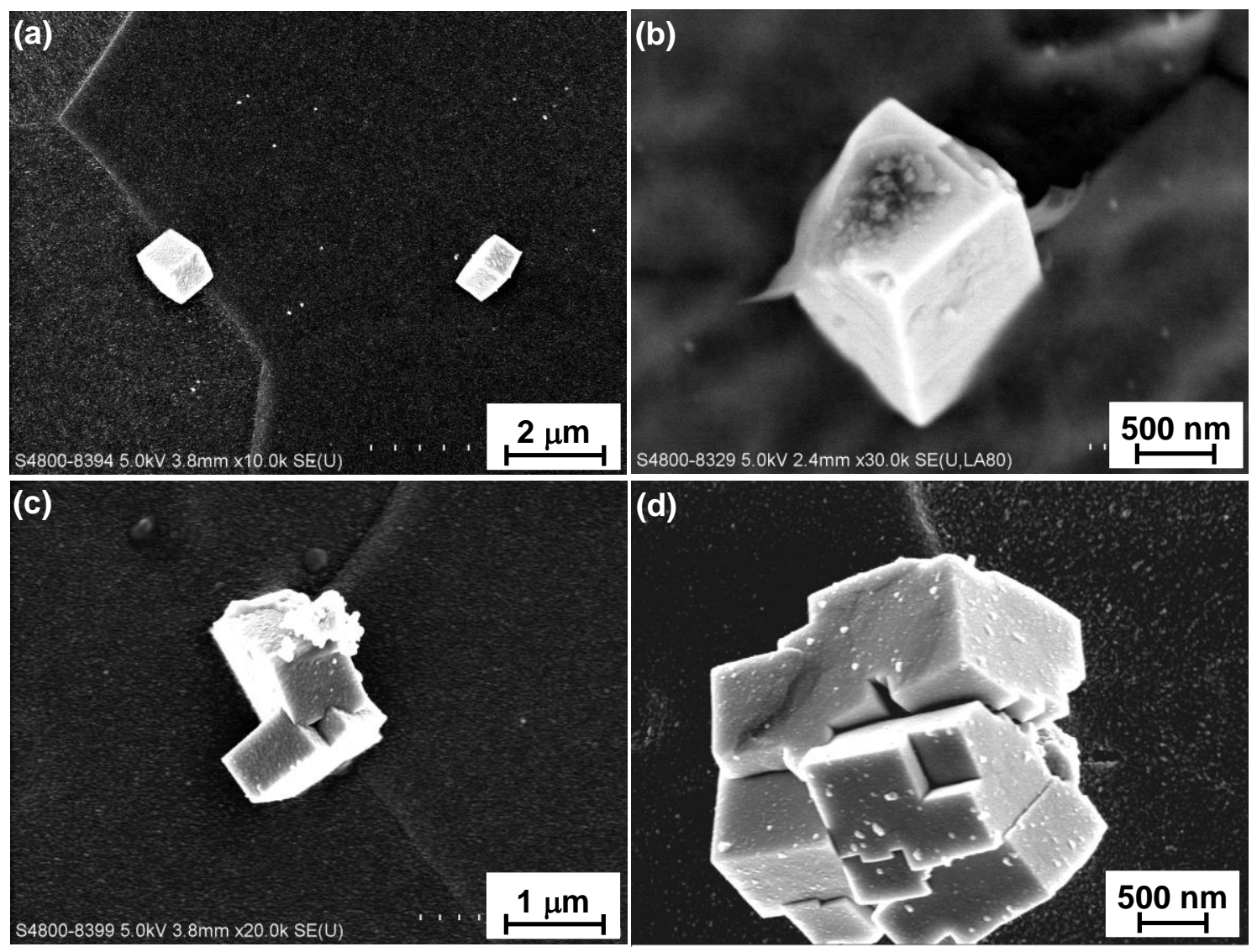

Fig. 3. FEGSEM micrographs of the alloy showing the positions, shapes and sizes of some representative cuboid particles. 

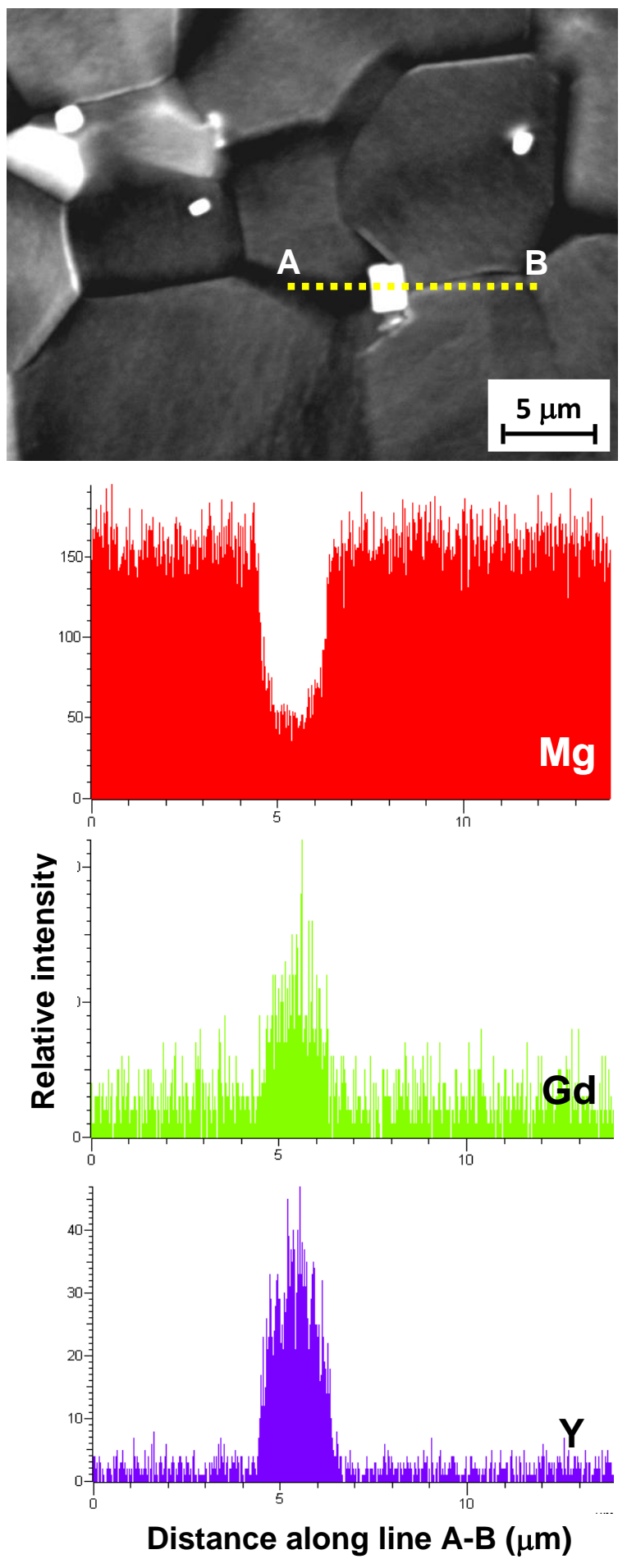

Fig. 4. SEM-EDS line scan along A-B showing the results for $\mathrm{Mg}, \mathrm{Gd}$ and $\mathrm{Y}$. 

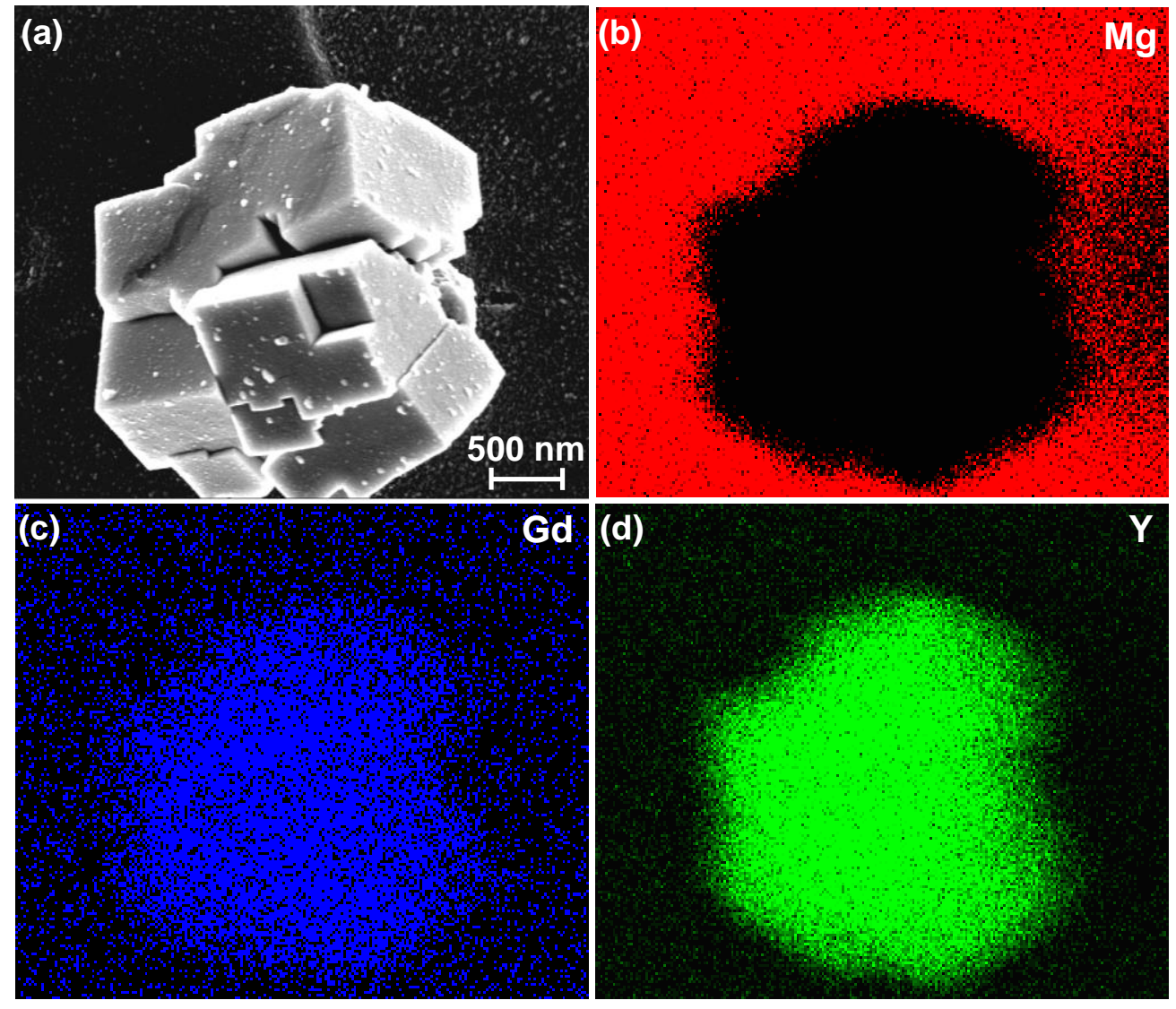

Fig. 5. (a) SEM micrograph of agglomerated cuboid particles and the corresponding elemental maps for (b) Mg, (c) Gd and (d) Y. 

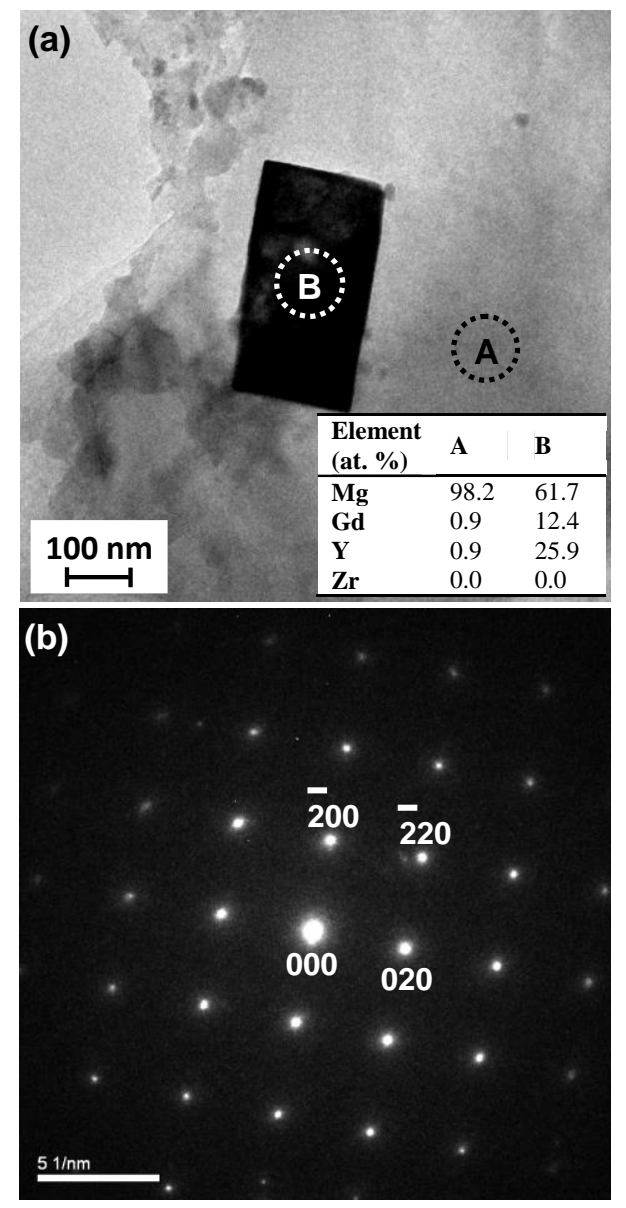

Fig. 6. (a) TEM micrograph and (b) corresponding SAED pattern of one of the cuboid particles with zone axis parallel to [001]. 


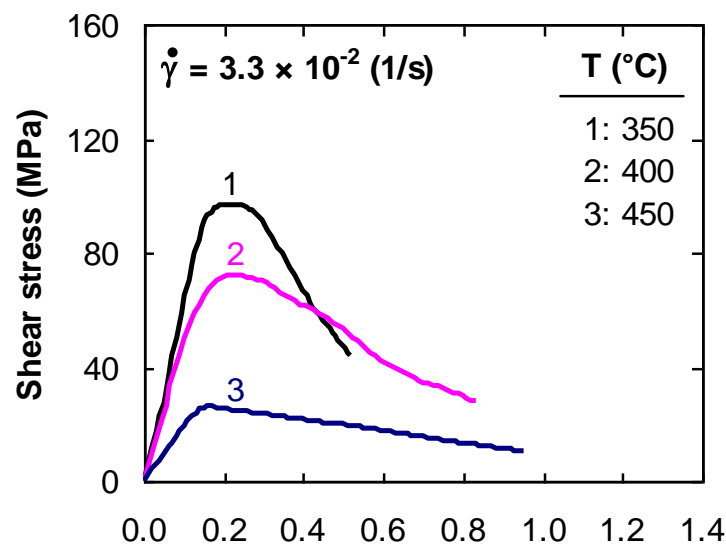

(a) Normalized displacement

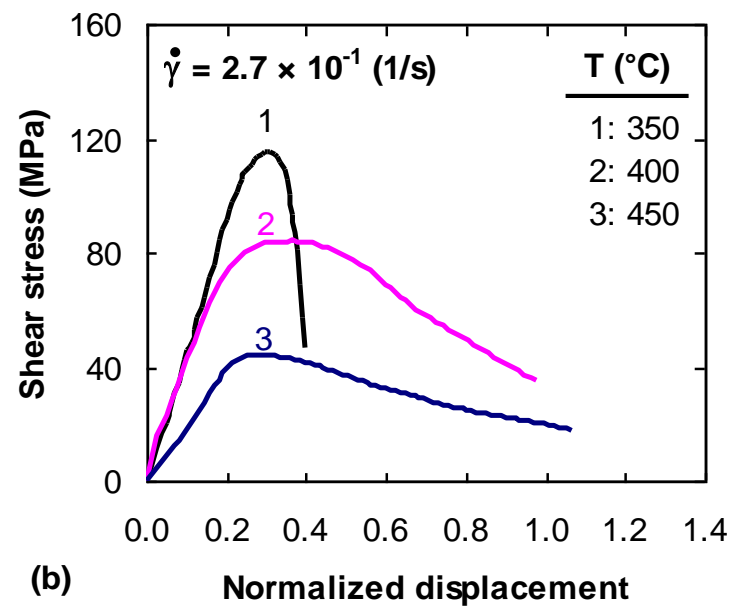

Fig. 7. SPT curves at different temperatures for shear strain rates of (a) $3.3 \times 10^{-2} \mathrm{~s}^{-1}$ and (b) 2.7 $\times 10^{-1} \mathrm{~s}^{-1}$. 


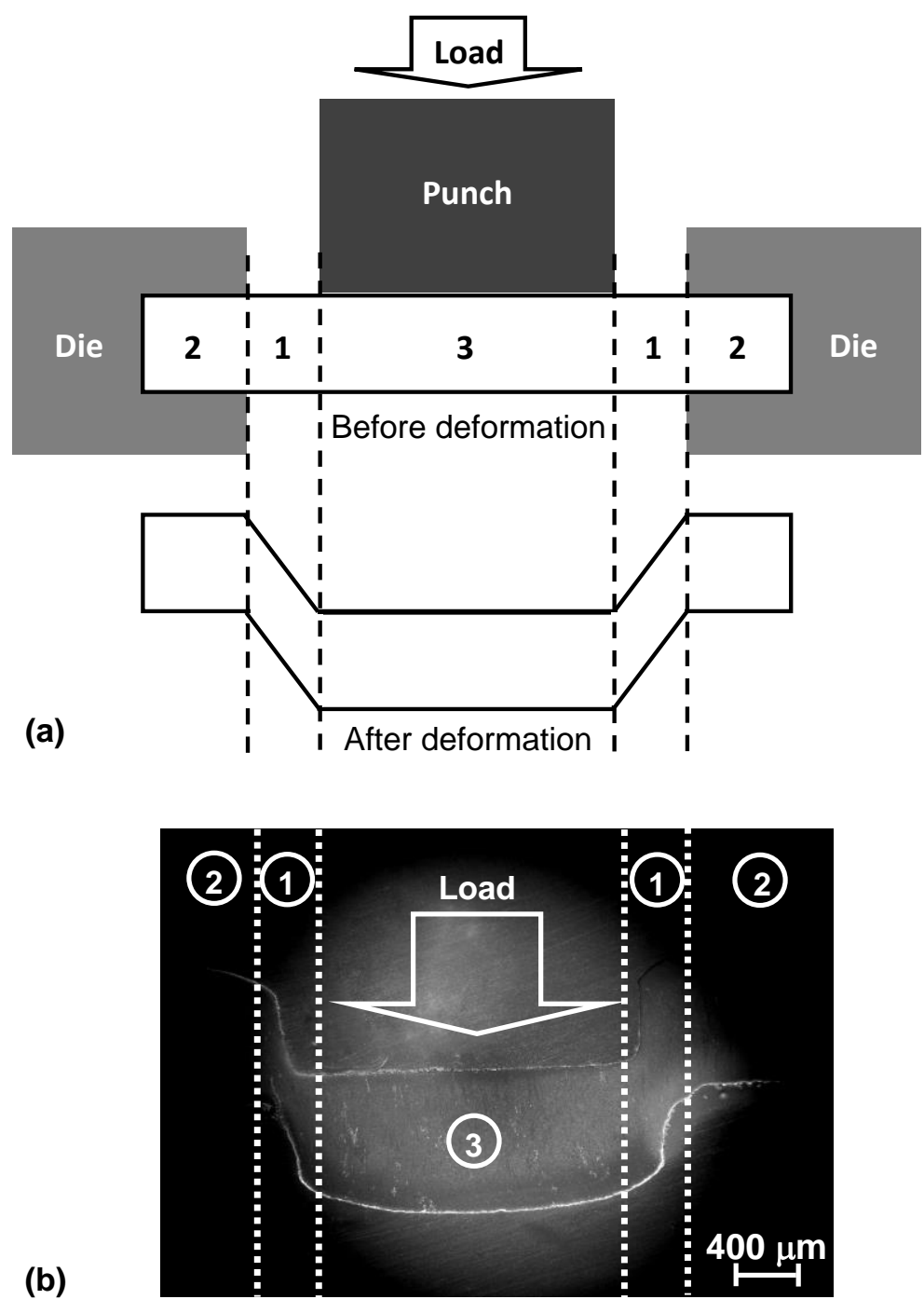

Fig. 8. (a) Schematic illustration of a sample before and after SPT and (b) a low magnification SEM micrograph of a sample after SPT showing areas corresponding to deformation (1), the die (2) and under the punch (3). 

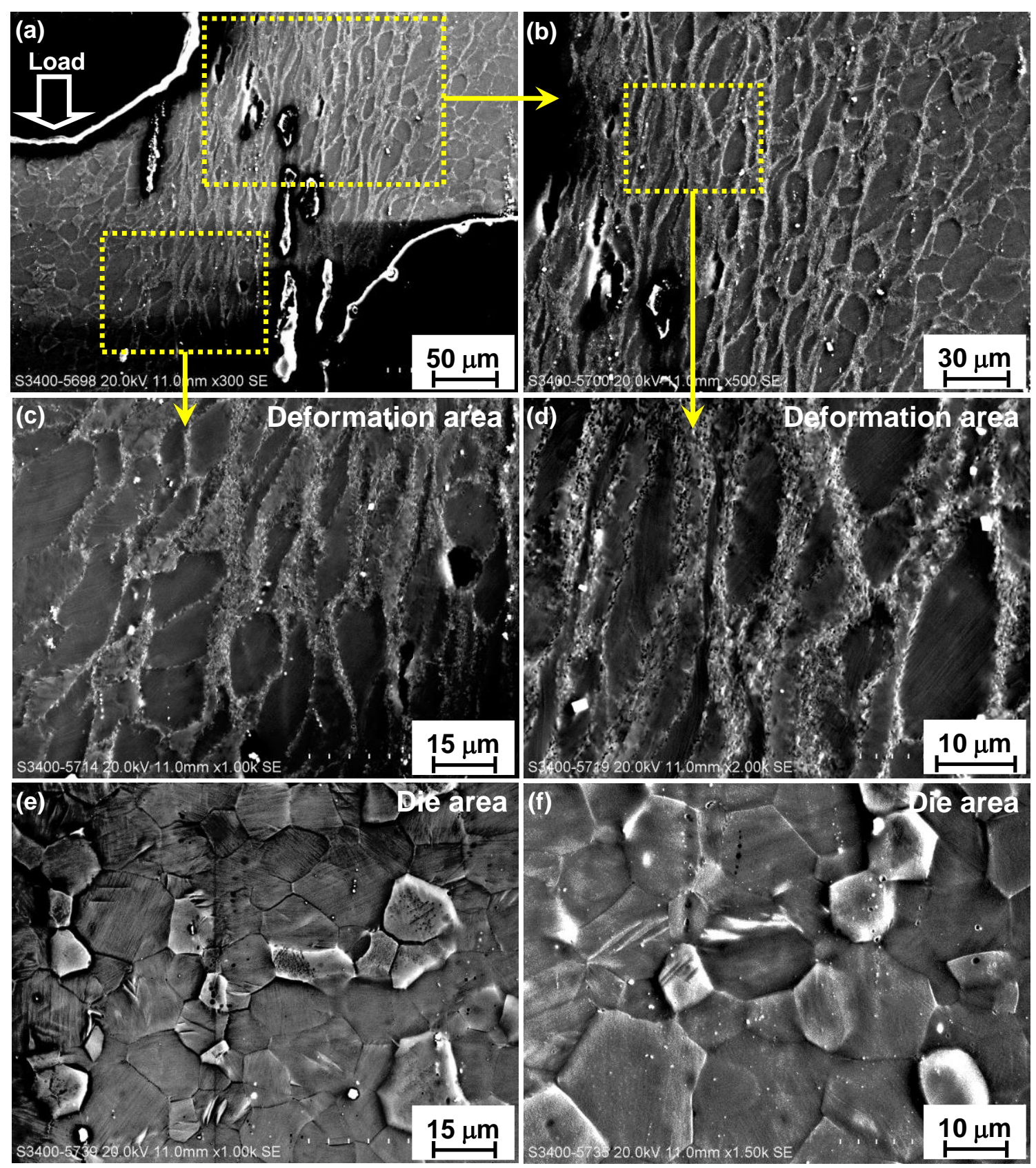

Fig. 9. SEM micrographs of the material after SPT at $350{ }^{\circ} \mathrm{C}$ under strain rate of $2.7 \times 10^{-1} \mathrm{~s}^{-1}$ : $(\mathrm{a}, \mathrm{b})$ deformation area and adjacent regions, $(\mathrm{c}, \mathrm{d})$ deformation area, and (e,f) die area. 


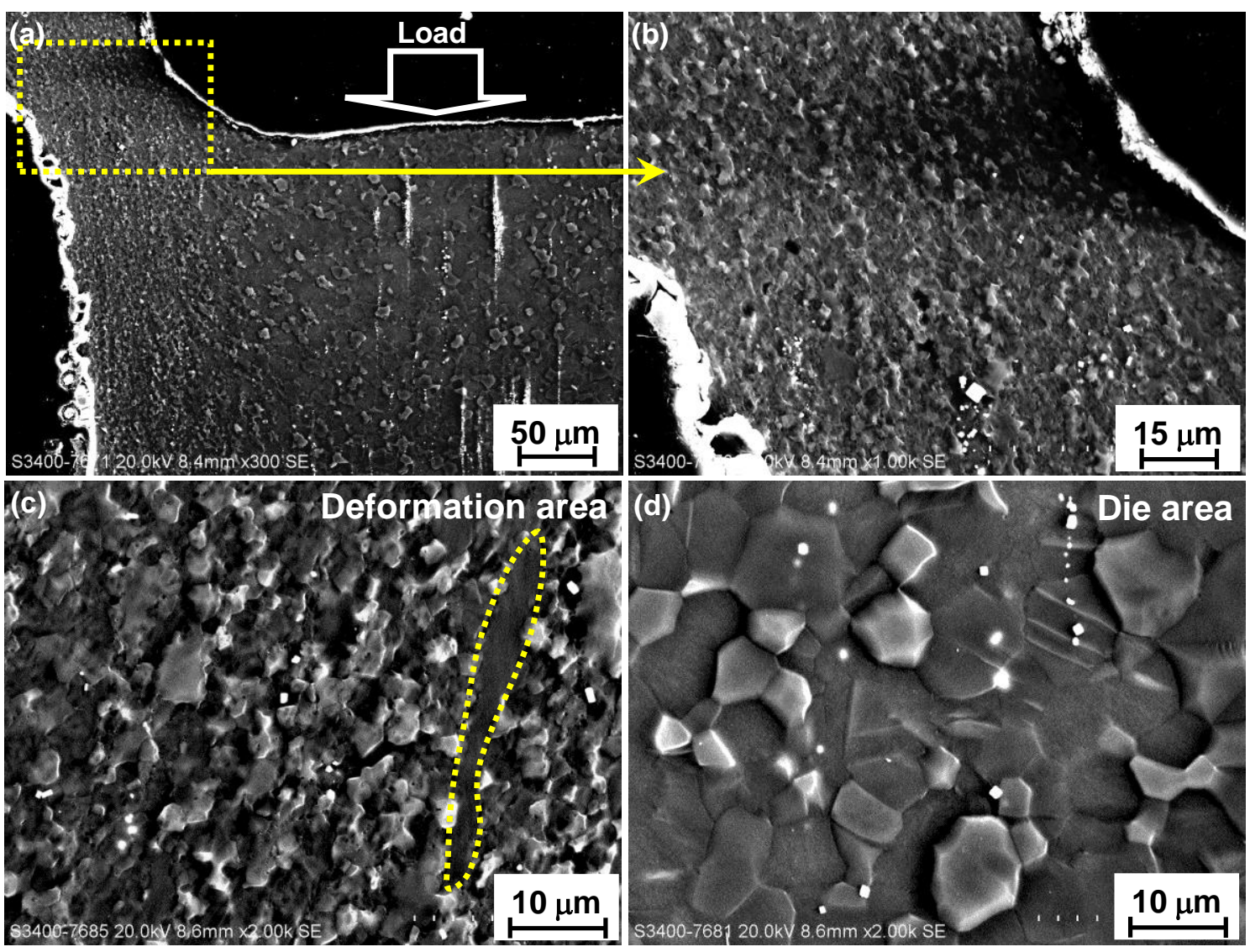

Fig. 10. SEM micrographs of the material after SPT at $400{ }^{\circ} \mathrm{C}$ under strain rate of $2.7 \times 10^{-1} \mathrm{~s}^{-1}$ : (a) deformation area and adjacent region, (b,c) deformation area, (d) die area. 

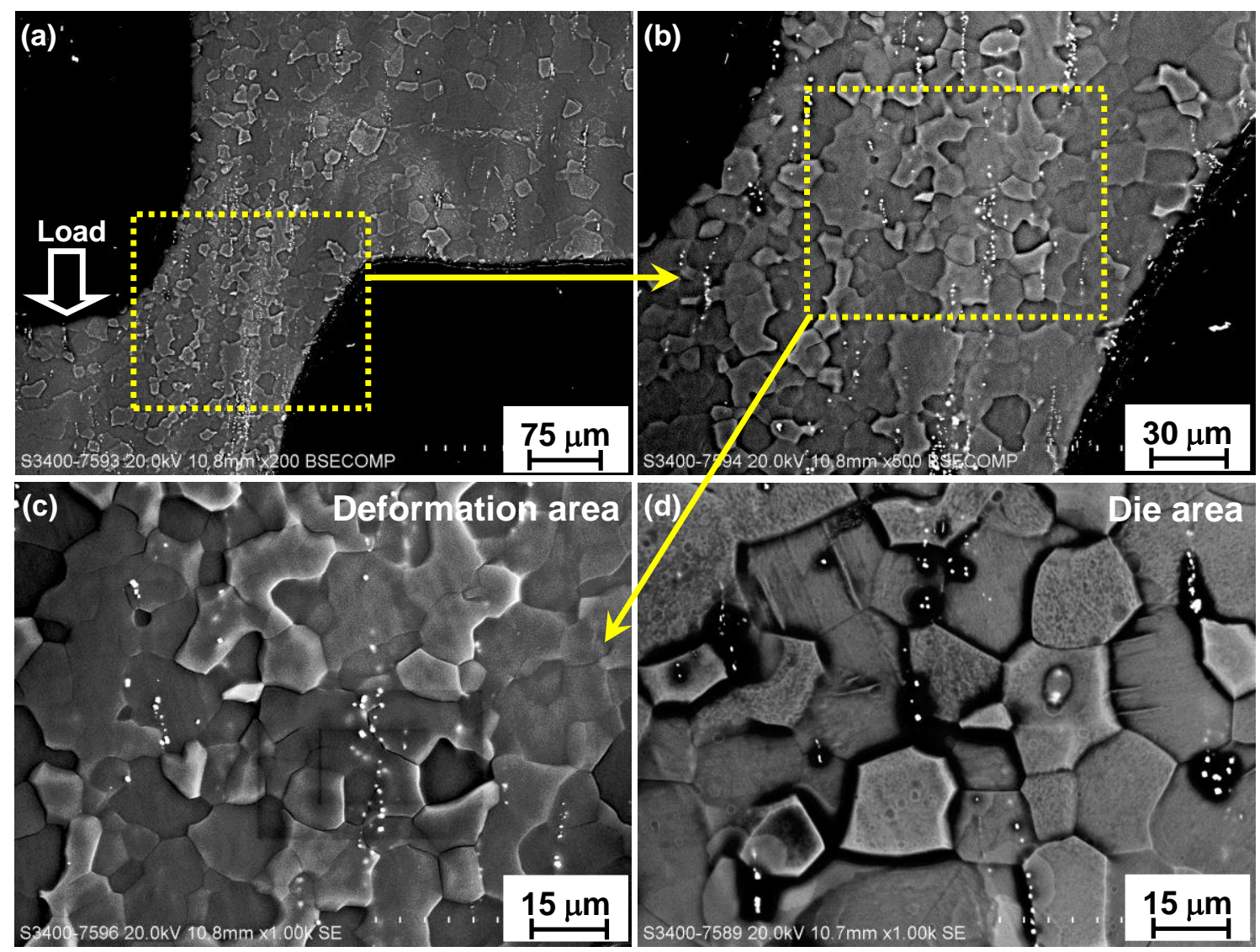

Fig. 11. SEM micrographs of the material after SPT at $450{ }^{\circ} \mathrm{C}$ under strain rate of $3.3 \times 10^{-2} \mathrm{~s}^{-1}$ : (a) deformation area and adjacent regions, (b,c) deformation area, and (d) die area. 


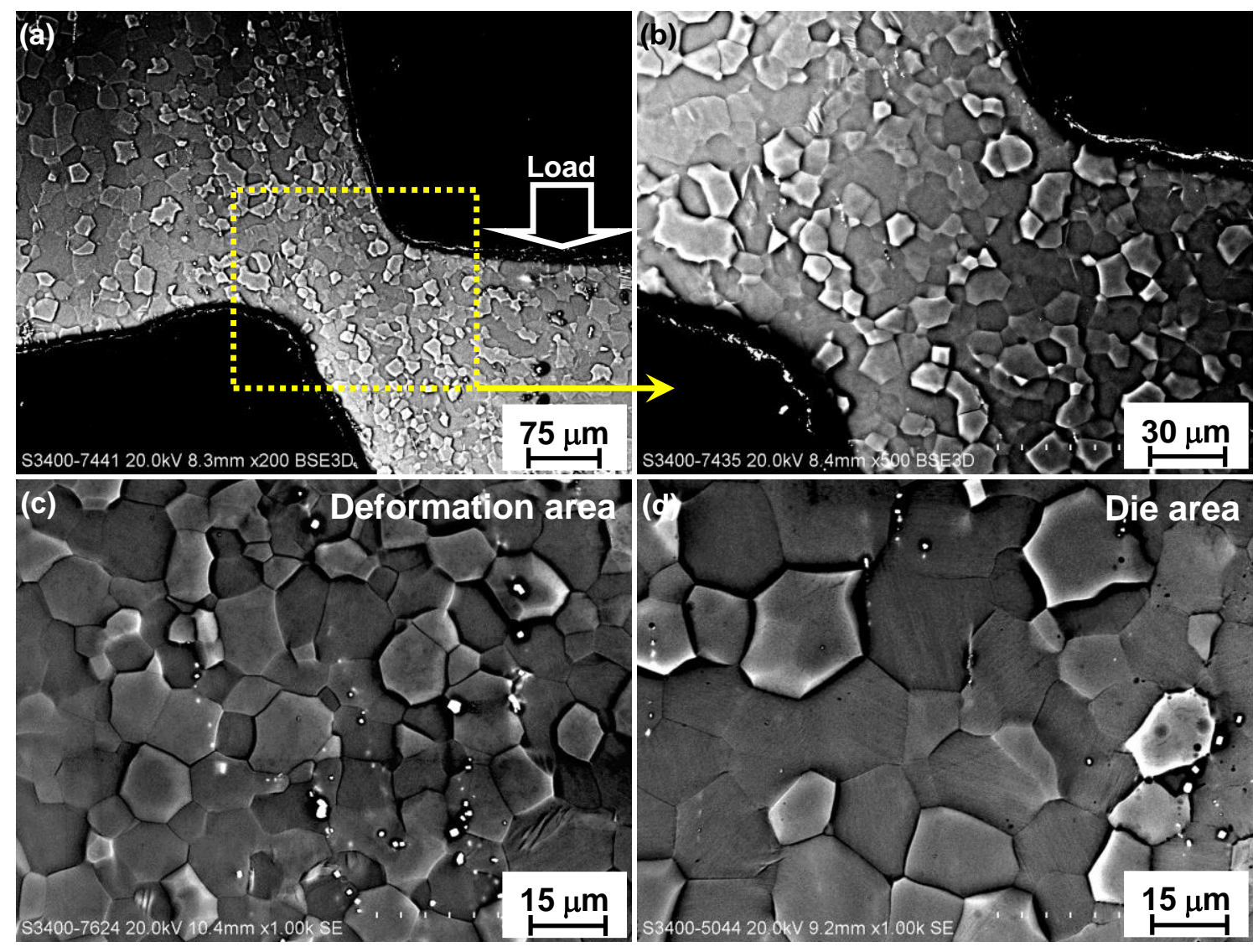

Fig. 12. SEM micrographs of the material after SPT at $450{ }^{\circ} \mathrm{C}$ under strain rate of $2.7 \times 10^{-1} \mathrm{~s}^{-1}$ : $(a, b)$ deformation area and adjacent regions, (c) deformation area, and (d) die area. 

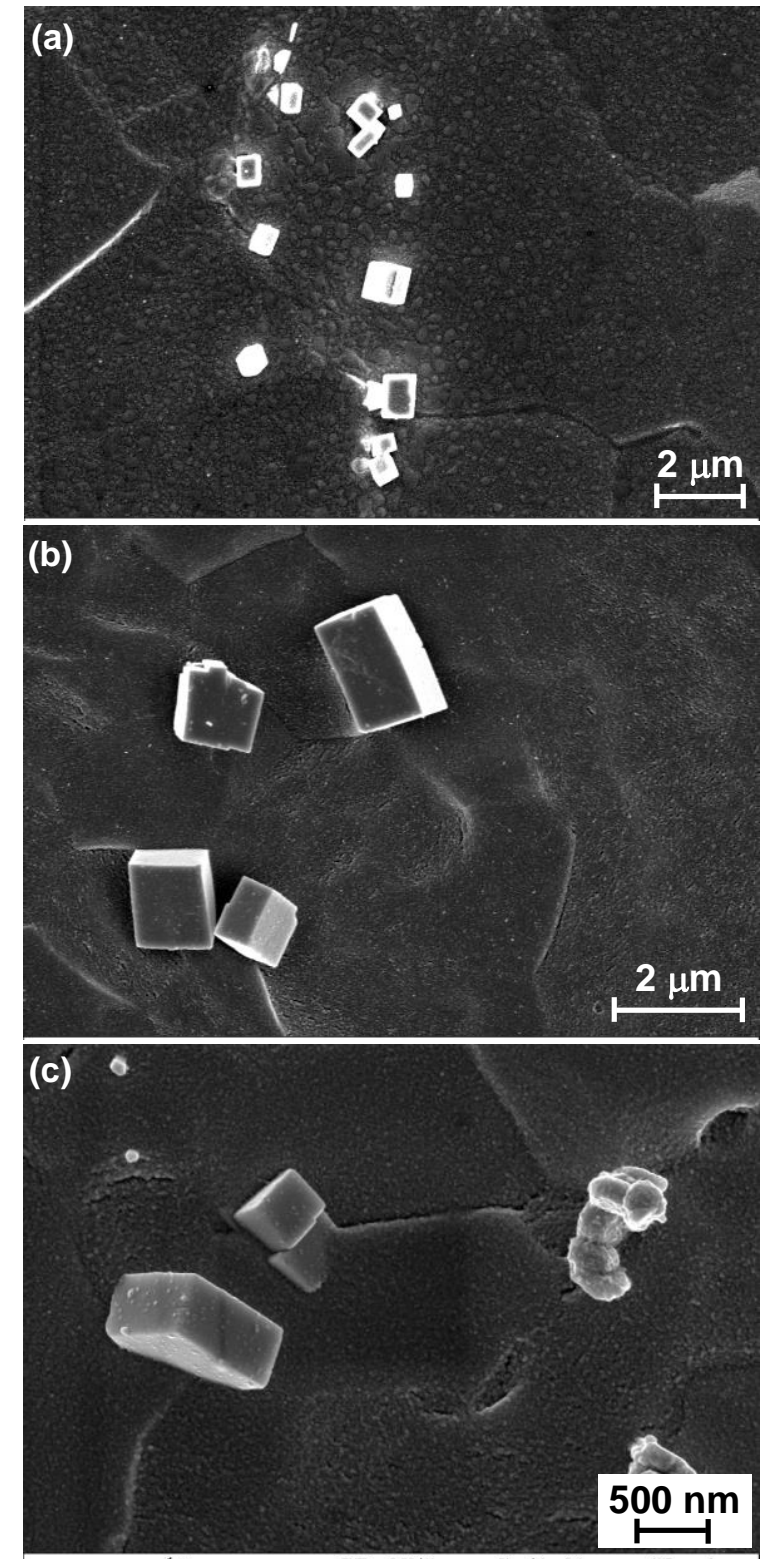

Fig. 13. High magnification FEGSEM micrographs of the material in the deformation area, showing the morphology of the cuboid particles after hot shear deformation at $400{ }^{\circ} \mathrm{C}$. 

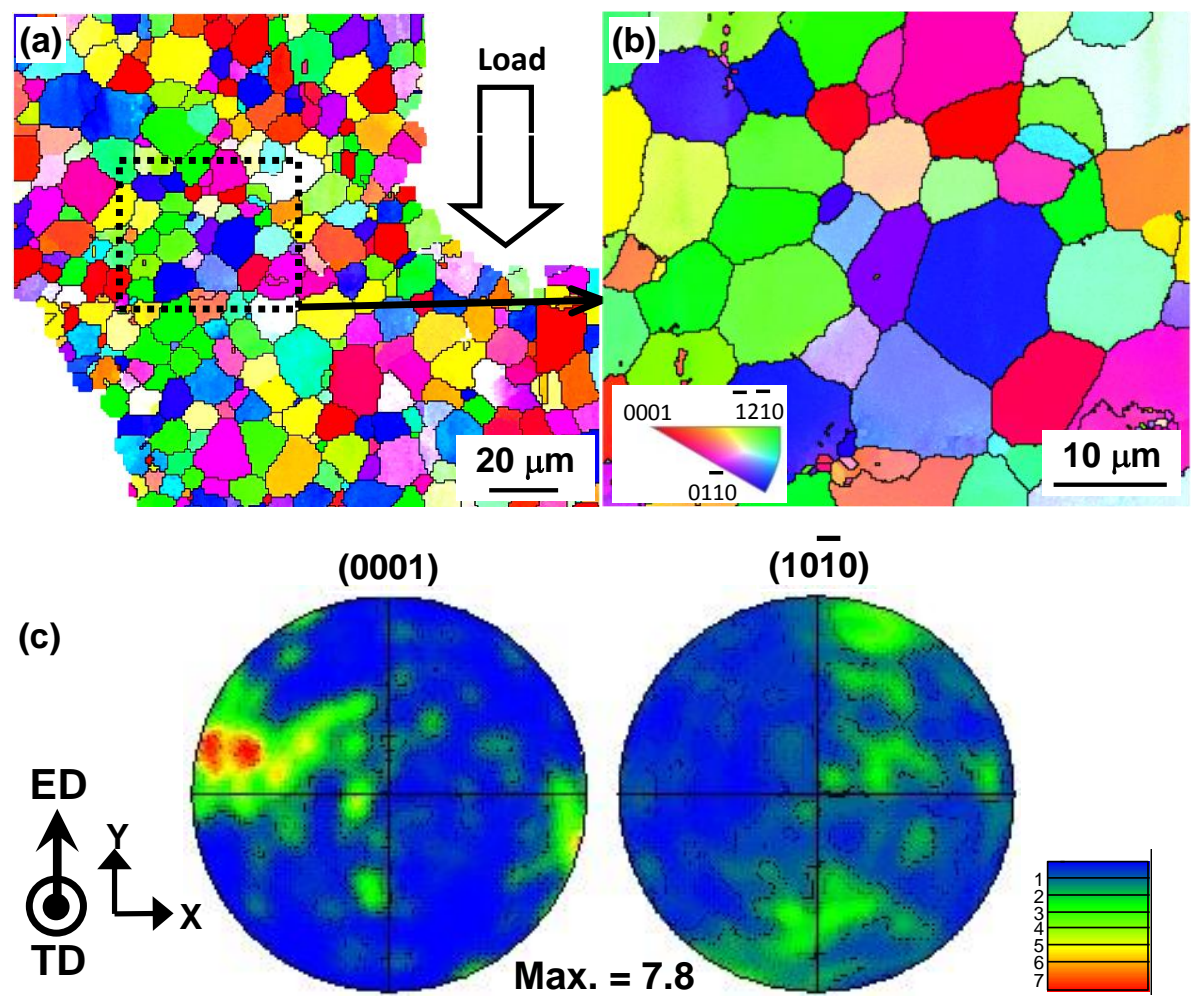

Fig. 14. EBSD orientation maps and pole figures of the material after SPT at $450{ }^{\circ} \mathrm{C}$ under strain rate of $3.3 \times 10^{-2} \mathrm{~s}^{-1}$. 